\title{
An artificial molecular machine that builds an asymmetric catalyst
}

DOI:

10.1038/s41565-018-0105-3

\section{Document Version}

Accepted author manuscript

Link to publication record in Manchester Research Explorer

\section{Citation for published version (APA):}

De Bo, G., Gall, M. A. Y., Kuschel, S., De Winter, J., Gerbaux, P., \& Leigh, D. A. (2018). An artificial molecular machine that builds an asymmetric catalyst. Nature Nanotechnology, 13(5), 381-385.

https://doi.org/10.1038/s41565-018-0105-3

\section{Published in:}

Nature Nanotechnology

\section{Citing this paper}

Please note that where the full-text provided on Manchester Research Explorer is the Author Accepted Manuscript or Proof version this may differ from the final Published version. If citing, it is advised that you check and use the publisher's definitive version.

\section{General rights}

Copyright and moral rights for the publications made accessible in the Research Explorer are retained by the authors and/or other copyright owners and it is a condition of accessing publications that users recognise and abide by the legal requirements associated with these rights.

\section{Takedown policy}

If you believe that this document breaches copyright please refer to the University of Manchester's Takedown Procedures [http://man.ac.uk/04Y6Bo] or contact uml.scholarlycommunications@manchester.ac.uk providing relevant details, so we can investigate your claim.

\section{OPEN ACCESS}




\title{
An artificial molecular machine that builds an asymmetric catalyst
}

\author{
Guillaume De Bo ${ }^{1}$, Malcolm A. Y. Gall ${ }^{1}$, Sonja Kuschel ${ }^{1}$, Julien De Winter ${ }^{2}$, Pascal \\ Gerbaux ${ }^{2}$ and David A. Leigh ${ }^{1}$ * \\ ${ }^{1}$ School of Chemistry, University of Manchester, Oxford Road, Manchester M13 9PL, United Kingdom \\ ${ }^{2}$ Organic Synthesis and Mass Spectrometry Laboratory, Interdisciplinary Center for Mass Spectrometry (CISMa), \\ University of Mons, 23 Place du Parc, B-7000 Mons, Belgium \\ *e-mail: david.leigh@manchester.ac.uk.
}

Biomolecular machines perform types of complex molecular level tasks that artificial molecular machines can aspire to. The ribosome, for example, translates information from the polymer track it traverses (messenger RNA) to the new polymer it constructs (a polypeptide). ${ }^{1}$ The sequence and number of codons read determines the sequence and number of building blocks incorporated into the biomachinesynthesized polymer. However, neither control of sequence ${ }^{2,3}$ nor the transfer of length information from one polymer to another (which to date has only been accomplished in man-made systems through template synthesis) ${ }^{4}$ are easily achieved in the synthesis of artificial macromolecules. Rotaxane-based molecular machines ${ }^{5-7}$ have been developed that successively add amino acids ${ }^{8-10}$ (including $\beta$-amino acids $^{10}$ ) to a growing peptide chain by the action of a macrocycle moving along a mono-dispersed oligomeric track derivatized with amino acid phenol esters. The threaded macrocycle picks up groups that block its path and links them through successive native chemical ligation (NCL) reactions ${ }^{11}$ to form a peptide sequence corresponding to the order of the building blocks on the track. Here we show that as an alternative to translating sequence information, a rotaxane molecular machine can transfer the narrow polydispersity of a leucine-ester-derivatized polystyrene chain synthesized by atom transfer radical polymerization (ATRP) $)^{12}$ to a molecular-machine-made homo-leucine oligomer. The resulting narrow molecular weight oligomer folds to an $\alpha$-helical secondary structure ${ }^{13}$ that acts as an asymmetric catalyst for the Juliá-Colonna epoxidation ${ }^{14,15}$ of chalcones.

To broaden the scope and potential utility of ribosome-inspired rotaxane synthesizing machines ${ }^{8-10,16,17}$ we decided to investigate translating length information from a parent polymer to a molecular-machinesynthesized product, with the aim of making a functional molecular object (Figure 1). Rotaxane-based machines that connect different building blocks in a particular order for sequence-specific synthesis require tracks built through multi-step synthesis. ${ }^{8-10}$ This is unnecessary for translating length information from a parent track to a new homo-polymer and so for this application we chose for the thread polystyrene bearing leucine ester groups with a narrow molecular weight distribution achieved through atom transfer radical polymerization (ATRP) of styrene with $p$-leucyloxystyrene. ${ }^{12} \mathrm{~A}$ polystyrene-based track should be inert under the molecular machine operation conditions and is relatively rigid compared to other common polyolefins. CPK models suggest that the macrocycle should slide along styrene regions of the track without significant hindrance but that a pendant leucine ester is sufficiently large to act as a barrier towards shuttling. Oligomers of leucine of sufficient length fold to a secondary structure that, like some other short peptides, ${ }^{18}$ have efficacy in asymmetric catalysis.

Machine 1 was assembled by extending ${ }^{9,10}$ one-barrier [2]rotaxane $\mathbf{2}$ with the leucine-bearing track 3 (Figure 2a). The synthesis of alkyne-terminated polymer $\mathbf{3}$ was accomplished through copolymerization of styrene (5) and $p$-leucyloxystyrene (6) by $\operatorname{ATRP}^{12}$ (Figure $2 \mathrm{~b}$ ). The reactivity ratio of styrene and a similar styrene ester, $p$-acetoxystyrene, is close to $1\left(r_{1}=0.89\right.$ and $\left.r_{2}=1.22\right),{ }^{19}$ and so we anticipated that a styrene/p-leucyloxystyrene couple would lead to a random copolymer. We targeted a monomer ratio of $11: 1$, representing an average distance of $\sim 22 \AA$ (unperturbed dimension) ${ }^{20}$ between adjacent ester groups. This spacing is similar to the distance $(\sim 20 \AA)$ between the building blocks in other rotaxane peptidesynthesizing molecular machines, ${ }^{8-10}$ which proved to be a good balance between the inter-barrier distance and the overall track length. ATRP polymerization of monomers 5 (220 eq.) and 6 (20 eq.) was carried out 
from the trimethylsilyl(TMS)-alkyne-terminated initiator 4 stopping at $22 \%$ conversion of the monomers, to afford polymer $\mathbf{7}$ in a process that concomitantly cleaved the silyl group. The resulting polymer had a narrow polydispersity $\left(\mathrm{M}_{\mathrm{w}} / \mathrm{M}_{\mathrm{n}}=1.10\right)$ and an average molecular weight of 7100 Da (Figure 2c). Its composition was in close agreement with the feeding ratio of $\mathbf{5}$ and $\mathbf{6}$, confirming the similar reactivities of the co-monomers. So as to prevent any undesired reaction of the vestigial benzylic bromide during operation of the machine, polymer $\mathbf{7}$ was subject to radical debromination mediated by $\mathrm{Bu}_{3} \mathrm{SnH}$ to form 3 (Figure 2b). ${ }^{21}$ Polymer track 3 was appended to [2]rotaxane 2 via copper(I)-catalyzed azide-alkyne cycloaddition ( $\mathrm{CuAAC}$ ) with $\mathrm{Cu}\left(\mathrm{CH}_{3} \mathrm{CN}\right)_{4} \cdot \mathrm{PF}_{6}$ to afford the elongated rotaxane $\mathbf{1}$ in $96 \%$ yield (Figure 2a). The composition of the machine-track composite 1 was determined by size-exclusion chromatography (SEC) (Figure 2c), matrix-assisted laser desorption ionization-time of flight (MALDI-TOF) mass spectrometry (Figure 2d) and ${ }^{1} \mathrm{H}$ and ${ }^{13} \mathrm{C}$ nuclear magnetic resonance (NMR) spectroscopy (see Supplementary Information Section 1).

Due to the polydispersity of the polystyrene, the machine-track composite 1 consists of a range of track lengths that also contain different numbers of leucine barriers. The ${ }^{1} \mathrm{H}$ NMR spectrum confirms an average of six leucine residues per machine, with a more detailed picture of the chain compositions revealed by MALDI and SEC (Figures 2c-e). The MALDI profile follows a Gaussian distribution with a median value around $9.6 \mathrm{kDa}$ (Figure $2 \mathrm{~d}$ ). In Figures $2 \mathrm{~d}$ and $2 \mathrm{e}$ the peaks are color-coded according to the number of leucine units incorporated into each machine-track conjugate. Determination of the relative abundances is complicated by the overlap of populations separated by five $p$-leucyloxystyrene units. However, the relative abundance of each population can be determined by combining the SEC data with the average composition obtained by NMR (see Supplementary Information Section 1.4), revealing that 1 is composed of molecular machines bearing 3-13 (detected by MALDI) leucine residues with the most abundant populations carrying 6-7 units.

Machine-track conjugate 1 was deprotected under acidic conditions to reveal the amines and thiol necessary for reaction. The active machine 8 was operated at $65{ }^{\circ} \mathrm{C}$ in DMF- $d_{7}$ for 4 days in the presence of triethylamine and triphenylphosphine (to minimise disulfide formation ${ }^{8-10}$ ) affording oligoleucine 9 (Figure 3a). Following a NCL mechanism, the thiolate reacts with the first leucine phenolic ester that blocks the macrocycle's path on the track to form a thioester. The amino acid residue is then transferred to the glycylglycine amine group, regenerating the catalytic thiolate group in the process (see Supplementary Information Section 2.6). The composition profile of the operation product, determined from the positive ion electrospray ionisation (+ESI) mass spectrum, reveals a narrow distribution of leucine oligomers ranging from 3-12 units and centred around 6 units (Figure 3c). These values are in close agreement with the theoretical composition of the operation product calculated from machine-track conjugate 1 (Figure $3 \mathrm{~b}$ ). The $M_{w} / M_{n}$ (1.02) and degree of polymerisation (DP) (6.5) values found for 9 closely match the theoretical values $\left(M_{w} / M_{n}=1.02\right.$, $\left.D P=7.4\right)$ determined from Figure $3 b$ (see Supplementary Information Section 1.5). This contrasts to the distribution obtained from a non-interlocked system (Figure 3d), where a dummy initiator was reacted in similar conditions with six equivalents of a barrier mimic (leucine cresol ester) which furnished only a short oligomer 11 (see Supplementary Information Section 2.8). The results indicate that the molecular machine operates processively and that the polydispersity of the track is translated into the product with high fidelity by the action of the artificial molecular machine.

The room temperature circular dichroism (CD) spectrum of the machine product, $\mathbf{9}$, in methanol has a maxima around $190 \mathrm{~nm}$ and two minima at 205 and $220 \mathrm{~nm}$ indicative of appreciable $\alpha$-helix character within the random coil conformation typical of short peptides ${ }^{13}$ (Figure $4 \mathrm{~d}$, yellow trace). ${ }^{22}$ Homo-leucine oligomers of sufficient length to form an $\alpha$-helix have been shown to act as effective asymmetric catalysts in the Juliá-Colonna epoxidation of chalcones. ${ }^{23}$ Under similar conditions (Figure 4c), both the short chain peptide 11 obtained from the dummy initiator ( 2-3 leucine residues attached to AlaGlyGly), and the machine product 9 ( 6-7 leucine residues attached to CysGlyGly) gave good conversions of furyl chalcone 
13 to the corresponding epoxide 14 (100 and $93 \%$, respectively), but with modest enantiomer excesses (e.e.) (16 and $26 \%$, respectively).

Oxidation of the thiol of 9 to the corresponding sulfonic acid occurs under the conditions of the JuliáColonna epoxidation, disrupting the $\alpha$-helix hydrogen-bonding network. We therefore carried out reductive radical desulfurisation of $\mathbf{9}$ to form the corresponding alanine derivative 12 (Figure 4a). ${ }^{24}$ The CD spectrum of the desulfurised product, 12, showed similar $\alpha$-helical secondary structure to 9 (Figure $4 \mathrm{~d}$, purple trace) and, pleasingly, in the Juliá-Colonna 12 afforded epoxide 14 with quantitative conversion and excellent enantioselectivity (92\% e.e.) in $18 \mathrm{~h}$ at room temperature (Figure 4a); higher conversion and similar asymmetric control to polyleucine itself. ${ }^{23}$

An artificial molecular machine has been developed that traverses a 50+ monomer unit long polystyrene track, picking up and connecting pendant building blocks to construct a new molecular chain with polydispersity information translated from the parent polymer. The time the machine takes to add 6-7 leucine residues from this track $(96 \mathrm{~h})$ is significantly longer than the $36 \mathrm{~h}$ required to add three amino acid residues in a previous peptide-synthesizing machine, ${ }^{8}$ as a consequence of both the size of the cyclic transition state and the length of track the macrocycle can access increasing with every amino acid addition. Biological synthesizing machines such as the ribosome ${ }^{1}$ overcome the second issue through ratcheting, ${ }^{5}$ a feature introduced in other synthetic molecular machines ${ }^{25-28}$ that might be usefully incorporated into future molecular synthesizer designs. Unlike shorter oligomers, the product of the oligoleucine synthesizing molecular machine folds to a persistent secondary structure, an $\alpha$-helix, that enables it to act as an effective asymmetric catalyst. The synthesis of a folded oligopeptide catalyst by a molecular machine that moves along a track is reminiscent of the way enzymes are produced in biology. Learning how to mimic aspects of the tasks performed by biomolecular machines with much simpler structures should prove useful in understanding how to design and build increasingly complex smallmolecule machines, ${ }^{29-31}$ in terms of both mechanism and what they can achieve.

\section{References}

1. Yonath, A. Hibernating bears, antibiotics, and the evolving ribosome (Nobel Lecture). Angew. Chem. Int. Ed. 49, 4340-4354 (2010).

2. Lutz, J.-F., Ouchi, M., Liu, D. R. \& Sawamoto, M. Sequence-controlled polymers. Science 341, 1238149 (2013).

3. ten Brummelhuis, N. Controlling monomer-sequence using supramolecular templates. Polym. Chem. 6, 654-667 (2015).

4. Polowinski, S. Template polymerisation and co-polymerisation. Prog. Polym. Sci. 27, 537-577 (2002).

5. Erbas-Cakmak, S., Leigh, D. A., McTernan, C. T. \& Nussbaumer, A. L. Artificial molecular machines. Chem. Rev. 115, 10081-10206 (2015).

6. Sauvage, J.-P. From chemical topology to molecular machines (Nobel Lecture). Angew. Chem. Int. Ed. 56, 11080-11093 (2017).

7. Stoddart, J. F. Mechanically interlocked molecules (MIMs)-molecular shuttles, switches, and machines (Nobel Lecture). Angew. Chem. Int. Ed. 56, 11094-11125 (2017).

8. Lewandowski, B., et al. Sequence-specific peptide synthesis by an artificial small-molecule machine. Science 339, 189-193 (2013).

9. De Bo, G., et al. Efficient assembly of threaded molecular machines for sequence-specific synthesis. J.

Am. Chem. Soc. 136, 5811-5814 (2014).

10. De Bo, G., et al. Sequence-specific $\beta$-peptide synthesis by a rotaxane-based molecular machine. J. Am. Chem. Soc. 139, 10875-10879 (2017).

11. Dawson, P. E., Muir, T. W., Clark-Lewis, I. \& Kent, S. B. Synthesis of proteins by native chemical ligation. Science 266, 776-779 (1994).

12. Matyjaszewski, K. \& Tsarevsky, N. V. Macromolecular engineering by atom transfer radical polymerization. J. Am. Chem. Soc. 136, 6513-6533 (2014). 
13. Andrews, M. J. I. \& Tabor, A. B. Forming stable helical peptides using natural and artificial amino acids. Tetrahedron 55, 11711-11743 (1999).

14. Juliá, S., Masana, J. \& Vega, J. C. 'Synthetic enzymes'. Highly stereoselective epoxidation of chalcone in a triphasic toluene-water-poly[(S)-alanine] system. Angew. Chem. Int. Ed. 19, 929-931 (1980).

15. Juliá, S. et al. Synthetic enzymes. Part 2. Catalytic asymmetric epoxidation by means of polyamino-acids in a triphase system. J. Chem. Soc., Perkin Trans. 1, 1317-1324 (1982).

16. Thordarson, P., Bijsterveld, E. J. A., Rowan, A. E. \& Nolte, R. J. M. Epoxidation of polybutadiene by a topologically linked catalyst. Nature 424, 915-918 (2003).

17. van Dongen, S. F. M., et al. A clamp-like biohybrid catalyst for DNA oxidation. Nat. Chem. 5, 945-951 (2013).

18. Lewandowski, B. \& Wennemers, H. Asymmetric catalysis with short-chain peptides. Curr. Opin. Chem. Biol. 22, 40-46 (2014).

19. Braun, D., et al. Analysis of the linear methods for determining copolymerization reactivity ratios, VII. A critical reexamination of radical copolymerizations of styrene. Angew. Makromol. Chem. 125, 161-205 (1984).

20. Young, R. J. \& Lovell, P. A. Introduction to Polymers, Third Edition. (CRC Press, 2011).

21. Coessens, V. \& Matyjaszewski, K. Dehalogenation of polymers prepared by atom transfer radical polymerization. Macromol. Rapid Comm. 20, 66-70 (1999).

22. Beychok, S. Circular dichroism of biological macromolecules. Science 154, 1288-1299 (1966).

23. Flood, R. W., et al. Efficient asymmetric epoxidation of $\alpha, \beta$-unsaturated ketones using a soluble triblock polyethylene glycol-polyamino acid catalyst. Org. Lett. 3, 683-686 (2001).

24. Wan, Q. \& Danishefsky, S. J. Free-radical-based, specific desulfurization of cysteine: A powerful advance in the synthesis of polypeptides and glycopolypeptides. Angew. Chem. Int. Ed. 46, 9248-9252 (2007).

25. Hernández, J. V., Kay, E. R. \& Leigh D. A. A reversible synthetic rotary molecular motor. Science 306, 1532-1537 (2004).

26. Chatterjee, M. N., Kay, E. R. \& Leigh D. A. Beyond switches: ratcheting a particle energetically uphill with a compartmentalized molecular machine. J. Am. Chem. Soc. 128, 4058-4073 (2006).

27. Serreli, V., Lee, C.-F., Kay, E. R. \& Leigh D. A. A molecular information ratchet. Nature 445, 523-527 (2007).

28. Wilson, M. R., et al. An autonomous chemically fuelled small-molecule motor. Nature 534, 235-240 (2016).

29. von Delius, M., Geertsema, E. M. \& Leigh, D. A. A synthetic small molecule that can walk down a track. Nat. Chem. 2, 96-101 (2010).

30. Kassem, S., Lee, A. T. L., Leigh, D. A., Markevicius, A. \& Solà, J. Pick-up, transport and release of a molecular cargo using a small-molecule robotic arm. Nat. Chem. 8, 138-143 (2015).

31. Kassem, S., et al. Stereodivergent synthesis with a programmable molecular machine. Nature 549, $374-$ 378 (2017).

\section{Acknowledgments}

We thank Prof. M. Turner and Dr J. Behrendt for assistance with the SEC instrumentation, Prof. J. Clayden and $\mathrm{Dr}$ M. De Poli for assistance with the CD measurements, and G. Smith for the MALDI analysis of earlier related systems. The UMONS MS laboratory thanks the Fonds National de la Recherche Scientifique (FRSFNRS) for its contribution to the acquisition of the Waters QToF Premier and Synapt G2-Si mass spectrometers and for continuing support. This research was funded by the Engineering and Physical Sciences Research Council (EP/P027067/1). We thank the Royal Society for a University Research Fellowship (to G.D.B) and a Research Professorship (to D.A.L.).

\section{Author contributions}

G.D.B., M.A.Y.G. and S.K. planned and carried out the experimental work. J.D.W. and P.G. performed the MS analysis of polymers 1 and 3. D.A.L. directed the research. All authors contributed to the analysis of the results and the writing of the manuscript. 


\section{Competing financial interests}

The authors declare no competing financial interests.

\section{Additional information}

Supplementary information is available in the online version of the paper. Reprints and permissions information is available online at www.nature.com/reprints. Correspondence and requests for materials should be addressed to D.A.L.

\section{Figure captions}

Figure 1 | Assembly of an artificial molecular machine system that builds an asymmetric catalyst. Translating polydispersity from a parent polymer to a molecular-machine-built oligomer that folds to a secondary structure that catalyses asymmetric epoxidation of a substrate.

Figure 2 | Assembly of molecular machine-track conjugate 1 by elongation of rotaxane 2 with polymer 3. a, Synthesis of 1: (i) $\mathrm{Cu}\left(\mathrm{CH}_{3} \mathrm{CN}\right)_{4} \cdot \mathrm{PF}_{6}, \mathrm{CH}_{2} \mathrm{Cl}_{2}:{ }^{\mathrm{t}} \mathrm{BuOH}(4: 1), \mathrm{RT}, 36 \mathrm{~h}, 96 \%$. b, Synthesis of polystyrene 3 by ATRP: (ii) $\mathrm{CuBr}$ (1 eq.), 4,4'-dinonyl-2,2'-dipyridyl (2.1 eq.), anisole ( $20 \mathrm{wt} \%$ ), $90^{\circ} \mathrm{C}, 24 \mathrm{~h}$, stopped after $22 \%$ monomer conversion. (iii) $\mathrm{Bu}_{3} \mathrm{SnH}$ ( 3 eq.), toluene, $85{ }^{\circ} \mathrm{C}, 1 \mathrm{~h}, 80 \%$. c, SEC traces of track 3 and machine 1 (THF, $1 \mathrm{~mL} / \mathrm{min}$, refractive index detector, normalised intensities are shown). d, MALDI-TOF-MS (+ve ion detection) of machine $1\left([\mathrm{M}+\mathrm{Na}]^{+}\right)$with peaks colour-coded according to the number of leucine residues present. e, an expansion of the region between $\mathrm{m} / \mathrm{z} 9520$ and 9750: adjacent similarly coloured signals correspond to machine-track conjugates that differ in length by a single styrene residue; adjacent differently coloured signals correspond to machine-track conjugates with different numbers of leucine residues. ran $=$ random co-monomer distribution.

Figure 3 | Operation of machine-track conjugate 1. a, Operation of machine 1: (i) $\mathrm{CH}_{2} \mathrm{Cl}_{2}: \mathrm{CF}_{3} \mathrm{CO}_{2} \mathrm{H}$ (4:1), $i \mathrm{Pr}_{3} \mathrm{SiH}$ (25 eq.), RT, 2 h, quantitative. (ii) $\mathrm{Et}_{3} \mathrm{~N}$ (50 eq.), $\mathrm{Ph}_{3} \mathrm{P}$ (3 eq.), $1 \mathrm{mM}$ in DMF- $d_{7}, 65{ }^{\circ} \mathrm{C}, 96 \mathrm{~h}, 50 \%$. b, Theoretical composition of the operation product based on Figure 2c. c, Observed composition of the operation product. $\mathbf{d}$, composition of leucine oligomer $\mathbf{1 1}$ obtained from a non-machine-promoted polymerisation: (i) $\mathbf{S 1 5}$ (1 eq.), leucine cresol ester $\mathbf{S 1 2}$ (6 eq.), $\mathrm{CH}_{2} \mathrm{Cl}_{2}: \mathrm{CF}_{3} \mathrm{CO}_{2} \mathrm{H}$ (4:1), RT, $45 \mathrm{~min}$, quantitative. (ii) $0.5 \mathrm{mM}$ in $\mathrm{DMF}, \mathrm{Et}_{3} \mathrm{~N}\left(50\right.$ eq.), $65^{\circ} \mathrm{C}, 96 \mathrm{~h}, 62 \%$. ran = random co-monomer distribution. $\mathrm{DP}=$ degree of polymerisation in terms of leucine residues.

Figure 4 | The $\alpha$-helicity of operation product oligoleucines before (9) and after (12) post-operational modification and their asymmetric Juliá-Colonna epoxidation of furyl chalcone 13. a, Reductive desulfurisation of 9. (i) 2,2'-Azobis(2-methylpropionamidine)dihydrochloride (V-50), ${ }^{\mathrm{t} B u S H}, \mathrm{Et}_{3} \mathrm{~N}$, tris(2carboxyethyl)phosphine (TCEP).HCl, DMF, RT, 22 h, 77 \%. b, Energy-minimized structure of seven-leucine 12 (DFT calculation, B3LYP 6-31*G) featuring a hydrogen bond-stabilised $\alpha$-helix (non-amide hydrogen atoms not shown for clarity). c, Epoxidation of furyl chalcone 13 using 9, 11 or 12 as catalyst. Conversions determined by ${ }^{1} \mathrm{H}$ NMR and e.e. by chiral HPLC. (ii) 9 (15 mol\%) or 11 (10 mol\%) or 12 (10 mol\%), urea. $\mathrm{H}_{2} \mathrm{O}_{2}$, 1,8-diazabicyclo[5.4.0] undec-7-ene (DBU), tetrahydrofuran (THF), RT, $4 \mathrm{~d}(\mathbf{9})$ or $18 \mathrm{~h}(\mathbf{1 1}, \mathbf{1 2})$. d, circular dichroism (CD) spectra (298 K, MeOH) of 9 (0.137 mM, yellow trace) and 12 (0.140 mM, purple trace).

\section{Methods section}

Deprotection of machine 1. A solution of machine 1 (10 mg, $1.06 \mu \mathrm{mol}, 1$ eq.) and $i \mathrm{Pr}_{3} \mathrm{SiH}(5.5 \mu \mathrm{L}, 26.40$ $\mu \mathrm{mol}, 25$ eq.) in $\mathrm{CH}_{2} \mathrm{Cl}_{2}(400 \mu \mathrm{L})$ and $\mathrm{CF}_{3} \mathrm{CO}_{2} \mathrm{H}(100 \mu \mathrm{L})$ was stirred for 2 hours at room temperature. The solvent was removed by azeotropic distillation with toluene $(2 \times 2 \mathrm{~mL})$. The solid residue was dried for 30 min under high vacuum, then washed with $\mathrm{Et}_{2} \mathrm{O}(5 \times 1 \mathrm{~mL})$. The residual crude solid $(8)$ was dried for $30 \mathrm{~min}$ under high vacuum, dissolved in DMF- $d_{7}$ (deuterated for ease of analysis) and operated without further purification. 
Operation of deprotected machine 8. A solution of freshly deprotected machine 8 (1.06 $\mu \mathrm{mol}, 1 \mathrm{eq}$.) in DMF- $d_{7}(1 \mathrm{~mL})$ was added to a capped $5 \mathrm{~mL}$ Biotage ${ }^{\circledR}$ vial loaded with $\mathrm{PPh}_{3}(0.8 \mathrm{mg}, 3.2 \mu \mathrm{mol}, 3$ eq. $)$ and purged with 5 vacuum/nitrogen cycles. The resulting solution was degassed via nitrogen sparging for 5 min. $\mathrm{NEt}_{3}\left(7.5 \mu \mathrm{L}, 53.0 \mu \mathrm{mol}, 50\right.$ eq.) was added and the solution was stirred at $65^{\circ} \mathrm{C}$ for $96 \mathrm{~h}$. An aliquot was removed for analysis $(100 \mu \mathrm{L})$ and diluted with LC-MS grade $\mathrm{MeOH}(1 \mathrm{~mL})$. A precipitate formed. The solution was filtered over a $0.45 \mu \mathrm{m}$ PTFE membrane. Mass spectrometry analysis of the filtrate confirmed the formation of the expected product while ${ }^{1} \mathrm{H}$ NMR of the precipitate indicated it consisted of the building-block-free thread. The filtrate was concentrated to dryness and purified by preparative TLC (Merck, $500 \mu \mathrm{m}, \mathrm{CH}_{2} \mathrm{Cl}_{2}: \mathrm{MeOH}: \mathrm{NH}_{3(\mathrm{aq})}$ [100:10:0.5], 1 elution). The fraction at $R_{f}=0.5$ was selected. The recovered solid was washed with $\mathrm{MeOH}(5 \times 1 \mathrm{~mL})$. The combined $\mathrm{MeOH}$ fractions were concentrated under reduced pressure to afford 9 as a colourless solid $(0.7 \mathrm{mg}, 50 \%)$.

\section{Data availability.}

The data that support the findings of this study are available within the paper and its Supplementary Information, or are available from the Mendeley data repository (https://data.mendeley.com/) with doi: 10.17632/3bybgz2jhz.1. 
Figure 1
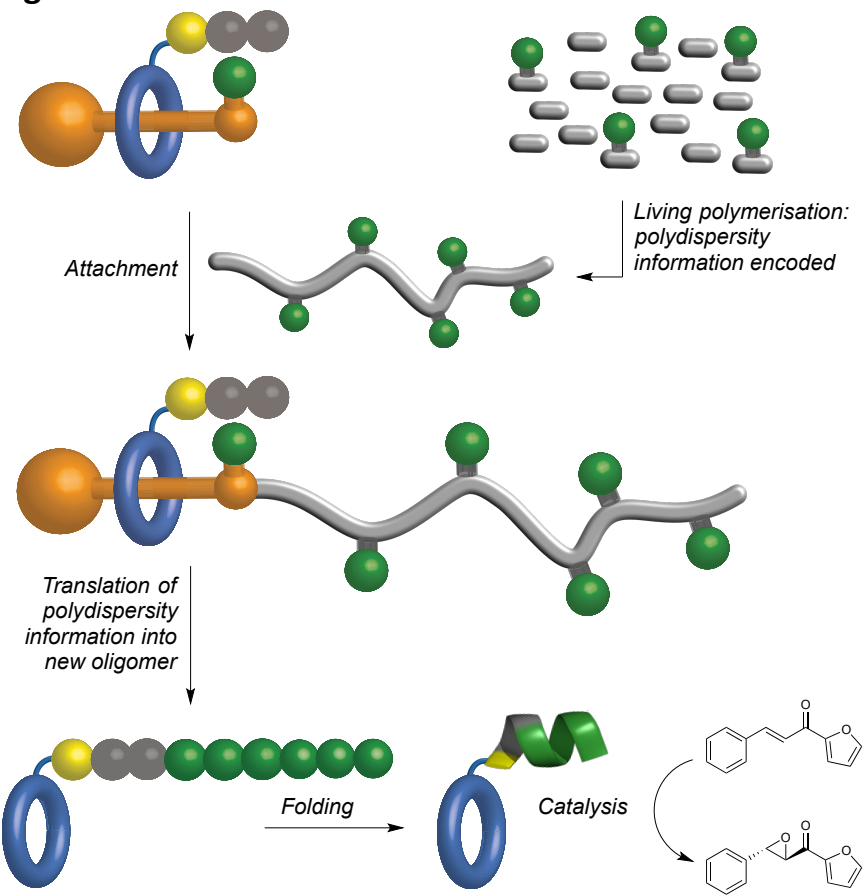

Figure 2
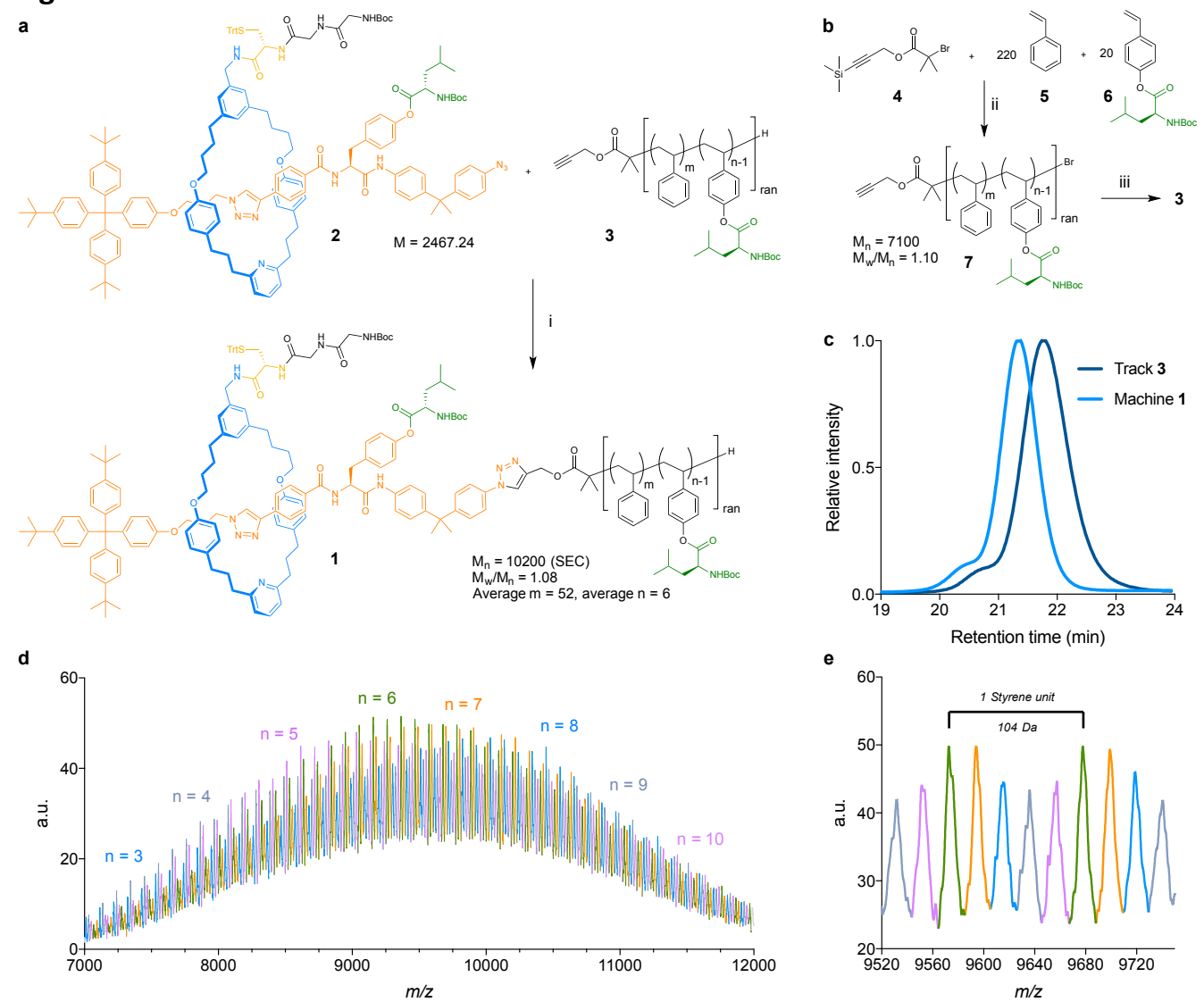
Figure 3
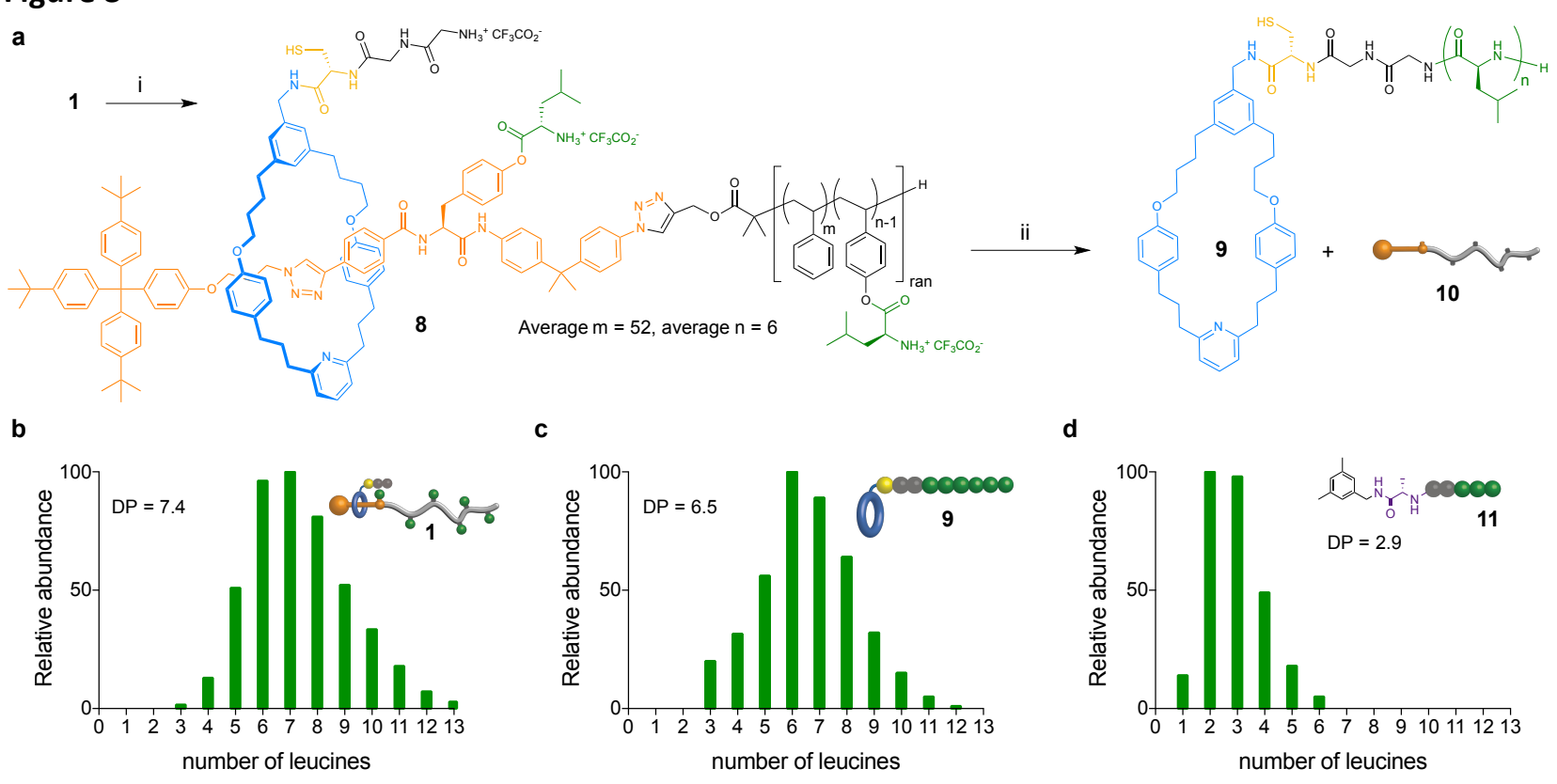

\section{Figure 4}
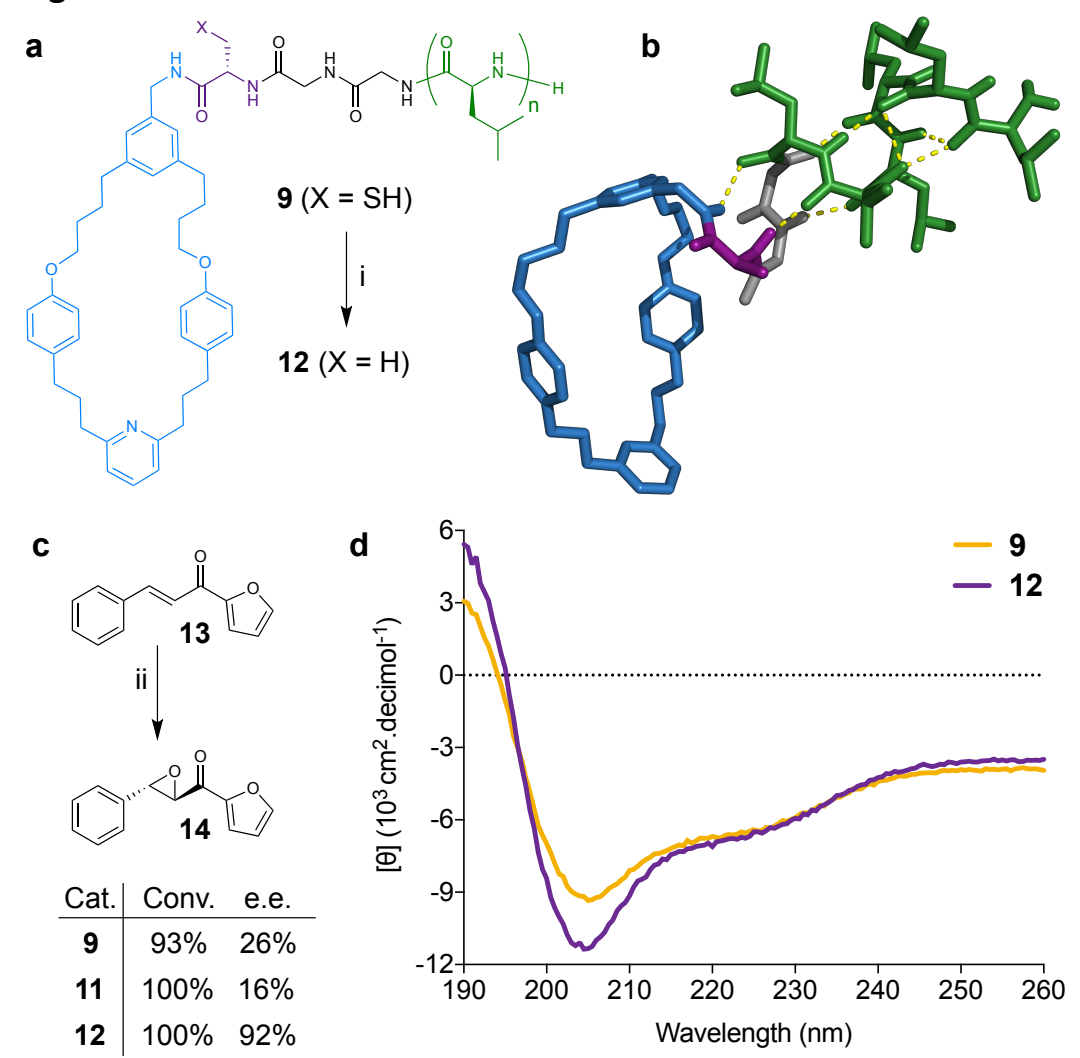